\title{
Frontal Bossing
}

National Cancer Institute

\section{Source}

National Cancer Institute. Frontal Bossing. NCl Thesaurus. Code C98242.

A skeletal deformity characterized by an unusually prominent forehead. Causes include acromeg aly, Hurler syndrome, Silver-Russell syndrome, and thalassemia major. 